One of the issues related to the fermentation of substrates made from biological raw materials in drum-type reactors is the difficulty of ensuring uniform mixing of their components, which adversely affects the quality of the compost produced.

Uniform mixing is achieved if the components of the material are fully dispersed at the free surface of the substrate segment. It was established that in order to fully disperse the particles of the substrate by a descending flow, it is necessary that the particles, which last fall from the blade, should reach the contact point of the drum's shell and the free surface of the substrate. To describe the established conditions, a mathematical model has been built, which links the equation of the boundary of the blockage of substrate particles in the drum and their fall along a parabolic trajectory. The equations are given to determine the kinematic parameters of the mixing process, provided that the substrate particles are dispersed in the transverse and longitude cross-sections of the drum.

The result of solving the differential equations is the equation of the linear speed of particle movement on the curved surface of the drum blade at which their full dispersal at the free surface of the substrate segment is achieved.

In order to conduct this research, an experimental drum reactor was designed and manufactured. It was experimentally determined at which humidity values of the substrate and the angular velocity of the reactor drum the uniformity of the distribution of components in the substrate reaches maximum values while the resulting compost meets the acting requirements in terms of microbiological indicators. The adequacy of the mathematical model to the experimental data has been confirmed.

The reported results are important because knowing the physicochemical properties of the substrate makes it possible to set such parameters of the process and equipment at which the high uniformity of mixing of substrate components is ensured, which affects the compost quality

Keywords: linear speed, uniformity of mixing, blade, friction coefficient, substrate humidity, fermentation

$\square$
UDC 662.659

DOI: $10.15587 / 1729-4061.2020 .217159$

\title{
DETERMINING OF THE INFLUENCE OF REACTOR PARAMETERS ON THE UNIFORMITY OF MIXING SUBSTRATE COMPONENTS
}

G. G o I u b
Doctor of Technical Sciences, Professor
Department of Tractors, Automobiles and Bioenergosystems*
E-mail: gagolub@ukr.net
M. T r e g u b
Doctor of Technical Sciences,
Associate Professor, Head of Department
Department of mechanization
and electrification of agricultural production
Bila Tserkva National Agrarian University
Soborna sq., 8/1, Bila Tserkva, Ukraine, 09117

E-mail: tregyb.m.i@gmail.com

A. Holubenko

Assistant

Department of Electrification, Automation of

Production and Engineering Ecology**

E-mail: anikagogobı@gmail.com

N. Ts y ve n kova

$\mathrm{PhD}$, Associate Professor

Department of Mechanics and Agroecosystems Engineering** Department of Tractors, Automobiles and Bioenergosystems* E-mail: nataliyatsyvenkova@gmail.com

V. Ch u b a

$\mathrm{PhD}$, Associate Professor

Department of Tractors, Automobiles and Bioenergosystems*

E-mail:vvchuba@ukr.net

M. Tereshchuk

Postgraduate Student

Department of Mechanics and Agroecosystems Engineering**

E-mail: marischa3127@gmail.com

*National University of Life and Environmental Sciences of Ukraine

Heroyiv Oborony str., 15, Kyiv, Ukraine, 03041

**Zhytomyr National Agroecological University

Staryi blvd., 7, Zhytomyr, Ukraine, 10008
Received date 18.10.2020

Accepted date 27.11.2020

Published date 15.12.2020
Copyright (C) 2020, G. Golub, M. Tregub, A. Holubenko, N. Tsyvenkova, V. Chuba, M. Tereshchuk This is an open access article under the CC BY license (http://creativecommons.org/licenses/by/4.0)
1. Introduction

Among the ways to improve the efficiency of agricultural production is the use of fertilizers made from organic sub- stances [1]. The effective method for processing organic matter into high-quality fertilizers is the composting process [2].

Structural success in the design of equipment to produce compost and a thorough study of the technology for making 
compost from organic raw materials indicate that this issue is given considerable attention to by modern technical research [3]. However, there are a series of technical issues that, given a lack of proper mathematical justification confirmed by the results from experimental studies, do not make it possible to obtain the expected results from the use of the specified technology [4].

One of the significant drawbacks in the process of composting organic raw materials is its low efficiency [3, 4]. The issue of improving the efficiency of the process of compost production has been tackled by using both manufacturing [5, 6] and structural methods [7]. In particular, technological methods include the following: ensuring optimal thermal mode at each stage of composting [8], the application of air aeration [9], etc. The structural methods include the design or improvement of the structure of basic units and working elements of equipment such as drum, stirrers, blades, modules for substrate loading and unloading the finished product, etc. [7].

An analysis of performance indicators of different types of equipment showed that various drum-type machines are the most effective for processing organic raw materials into compost $[10,11]$. This is predetermined by a series of economic and operational advantages of such equipment.

However, the maximum simplicity of the design of drumtype reactors is combined with the behavior of the processed environment, which is extremely difficult to describe. The effect of the centrifugal force and gravitational fields is the cause of the complex movement of components in the substrate that fills a rotating drum, which greatly complicates the uniformity of mixing these components and modeling working characteristics. The absence of a generally accepted methodology for predicting the substrate behavior that fills the reactor's drum significantly limits the effectiveness of the implementation of manufacturing processes when using this equipment.

The implementation of reactor working processes is predetermined by the nature of the substrate particle movement mode in the transverse and longitude cross-sections of the rotating drum. Therefore, it is a relevant task to establish patterns of change in the kinematic and geometric parameters of substrate particle movement.

\section{Literature review and problem statement}

Drum-type reactors are widely used not only to produce compost but also in the chemical, food, pharmaceutical, mining, and other industries [12]. The main function of these reactors is the mixing of substances with different specific weight, granulometric composition, and physical-chemical properties [13].

Compared to other types of machines to produce compost, drum-type reactors are widely used due to the capability to ensure the specified uniformity of mixing the substrate components. Their advantages include high performance, the preservation of properties of substrate components, minimal energy consumption, a low noise level during operation, the ease of operation and installation [10-13].

The movement modes of substrate particles in drum-type reactors exert a significant impact on the implementation of manufacturing processes and the energy intensity of drive units. Modeling the kinematic parameters of such modes of movement is of interest for studying the effectiveness of different rotary systems. A given issue is quite complex; that contributes to improving conventional methods, as well as searching for new analytical and experimental methods to investigate it [14].

According to [13], the quantitative characteristic of the completion of the mixing process is the degree of homogeneity of the substrate. That is, the mass ratio of the content of the control component in the test being analyzed to the content of the same component in the ideal substrate, expressed as a percentage or fraction of unity. The mixing process proceeds faster and more steadily in case of mixing homogeneous components in the substrate. In practice, substrates consist of particles of different sizes, shapes, non-uniform in density and physical-chemical properties (manure, straw, peat, tree leaves, bird droppings, etc.), so the process proceeds more slowly and less steadily. After conducting a study of the impact of the concentration of different components in the substrate on qualitative indicators of the composting process, the authors of [13] did not determine the uniformity of the distribution of components in the substrate during the research. The study of uniformity of the distribution of components in the substrate is an important parameter that characterizes the uniformity of the substrate and makes it possible to assert the adequacy of the results obtained.

Work [15] applied modeling to describe the movement of non-sphere-shaped particles, which have, compared to spherical particles, stronger relationships and, consequently, low looseness, and a greater inclination angle; however, the impact of rotation frequency on stirring was not given enough attention.

According to study [16], it was found that the transition to cascading mode from the rolling mode depends not only on the level of filling the drum, particle size, and Froude's number but also on their geometric shape. A significant disadvantage of the proposed mathematical model of evenness of the distribution of mixture components is that the authors accepted a certain general geometric shape of the mixture components, which differ only in weight. The variety of shapes of source material and the impracticality, sometimes the impossibility, to obtain their similar geometric shape significantly complicates the application of the reported results for practical use.

Work [17] applied a discrete-element method to examine the effect of the particle shape of the material, the drum's frequency of rotation, and the roughness of the end walls of the short drums on the degree of mixing. It was found that for short drums the value of effective contact area of the material with the drum walls has a greater impact on the quality of mixing of material components compared to the speed of rotation. In this case, the greater the length of the drum, the lower the degree of friction of the components of the material against the end walls.

Study [18] investigated the influence of the drum's frequency rotation and the ratio of the drum's end and side walls on axial dispersion of the material. It is proved that the ratio of the sides of the drum almost does not change the amount of axial dispersion of the material as opposed to the frequency rotation of the drum. The higher the drum frequency rotation, the lower the axial dispersion value.

However, the results reported in $[17,18]$ are typical for mixing dry materials. When composting organic materials, a certain influence on the nature of the interaction of the drum wall with the material would be exerted by humidity. Therefore, the application of these findings for composting organic materials requires clarification and consideration of the humidity of the material as a variable factor. In addition, when studying the parameters of the process of movement of particles of substrate components in the drum, it is necessary to 
take into consideration the effect of humidity on the coefficient of friction of particles of the substrate at the curved surface of the drum blades.

Papers [15-19] also attempted to transfer some environment properties to the examined model by using the Froude criterion and Reynolds criterion. Some criteria used in work [19] could be applied to evaluate the mixing processes of complex media as an addition to the parameters specified above. Employing a discrete-element method, the trajectory of dry mixture particle movement was investigated when falling from a radial blade and the effect of particle sizes on the distribution of the speeds of their movement in drums with the rotation frequencies of 5-15 rpm [20]. It was established that with a stable value of the Froude's number, a significant influence on the parameters of the velocity field is exerted by the ratio of size of the particles of the material to the diameter and length of the drum. The application of criteria reported in works [15-20] is advisable in the study of the processes of mixing bulk materials of different shapes and weights; however, composting organic materials faces a variety of shape, structure, property of mixture components, whose humidity could reach $80 \%$. Therefore, using the reported results in the production processes of organic compost requires additional research and refinement.

Study [21] demonstrated the practical application of a discrete-element method when modeling actual industrial processes. The study analyzed the agitation of different combinations of binary mixtures, which varied in density and size. The study's lack of influence of other variable physical and mechanical properties of materials on agitation parameters complicates the application of findings in practical production tasks when mixing organic materials.

The parameters of the movement of particles of the material in rotating drums are also represented by numerical algorithms in [22-24]. The algorithm of molecular dynamics [22] and a finite-element method employing a Mohr-Coulomb elastic model [16] were used in the cited works [22-24] to study the behavior, distribution of speeds, and a zone of filling the drum with the material's particles. The simulation was performed in the programming environment PLAXIS 3D and SCAD Office.

A multi-phase model of the computational hydrodynamics method was used in [23] to describe the pattern of drum filling depending on a change in the angular velocity and filling factor. To determine the movement of filling a slowly rotating drum with the material, the authors of [24] applied a multi-scale model employing a finite-element method. The cited work [24] also outlines the advantages of a given method compared to the method of discrete elements.

However, these methods have not become widely used since the accuracy of numerical calculations is significantly limited due to the pre-uncertain initial conditions and the non-physical nature of boundary conditions [25]. The results reported in works [22-25] are typical of the operation of drum mixers without blades and when mixing materials that have a defined granulometric composition of the mixture components. The use of the reported models to describe the process of agitating organic compost would lead to significant deviations from the given results.

There are several studies in which the kinematics of the movement of the material's particle in the transverse and axial cross-sections of the rotating drum depending on the frequency of the rotation and relative particle size were examined by experimental methods. These are the following methods: high-speed video recording followed by image processing [26], a method of tomographic analysis of material behavior when filling a rotating drum [27]. However, due to the limited resolution of the measuring equipment, the reliability and accuracy of the results from experimental studies is significantly understated. The results obtained in this way could be interpreted to derive characteristic dependences but the range of their use is limited by the similarity of the physical and mechanical properties and granulometric composition of materials.

Due to the limitation of capabilities in determining the geometric and speed parameters of the movement of particles of the material in a rotating drum, both numerical and experimental methods require comparing the results of their application. Both the low reliability of control devices and the complexities of mathematical calculations reduce the effectiveness of known techniques to determine the kinematic parameters of the movement of the particle of the material in a rotating drum. Therefore, the analytical and experimental studies' results, reported in works [15-27], are approaching the actual modes of movement of the studied environment only in terms of external features and qualitative characteristics. In addition, they mainly relate to dry loose materials. There are no such studies in the multicomponent substrates with humidity up to $80 \%$. In addition, according to quantitative indicators, the data from works [15-27] differ significantly.

Given the above, there is a need for the theoretical and experimental substantiation of the structural and kinematic parameters of drum-type reactors to ensure the uniform mixing of components in substrates made from organic raw materials.

\section{The aim and objectives of the study}

The aim of this study is to determine the impact of reactor and process parameters on the uniformity of mixing the component particles in a substrate. This would make it possible to improve production efficiency.

To accomplish the aim, the following tasks have been set:

- to determine the dependence of the value of the linear movement speed of substrate particles at which there is a complete dispersal of the material over a free surface of the substrate segment on the process geometric and kinematic parameters dependent on it;

- to experimentally investigate the impact of the angular velocity of a reactor's drum and the substrate humidity on the value of the linear movement speed of the substrate particles, which affects the uniformity of mixing the substrate components.

\section{Materials and methods to study the parameters} of a drum-type reactor

An experimental drum-type reactor was designed and manufactured to perform an experimental study into the uniformity of distribution of the components of bioorganic raw materials in a substrate (Fig. 1).

The reactor included electric motor 1 , gearbox 2 , frame 3 , bearing support 4 , drum 5 , axle 7 , adjustable rack 8 , connecting coupling 9 , and fitting with female thread 10 . The reactor's drum 5 had loading and unloading hatch 6 covered with a lid. Inside drum 5, along the entire length and evenly around the perimeter, curved blades 11 were stationary fixed. 


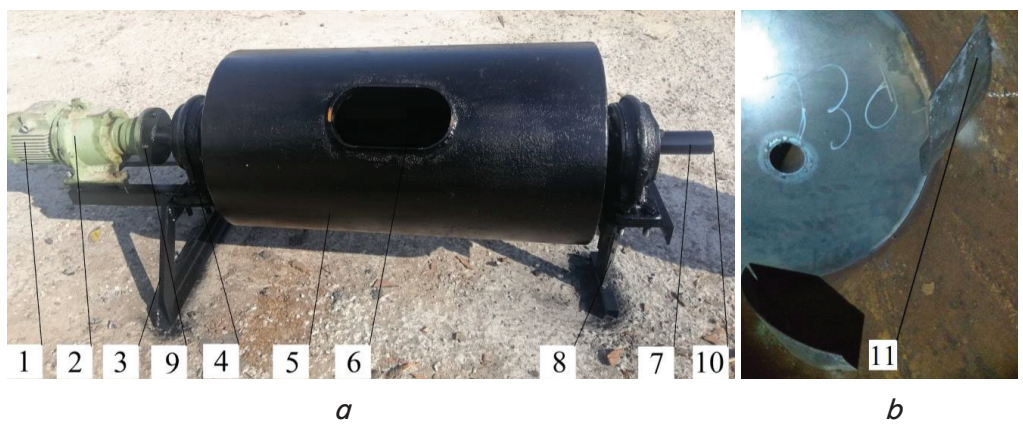

Fig. 1. Experimental drum-type reactor: $a$ - physical appearance; $b$-stationary fixed blades

Loading the substrate and unloading the compost occurs periodically, which is acceptable for the experimental installation. Hatch 6 is equipped with an automatic pressure control valve, which opens with a pressure increase of more than $2 \mathrm{~atm}$.

During the rotation of the drum, due to the action of its combined elements, the components of the substrate are mixed. At the same time, radial blades and four longitudinally placed tubes with nozzles (not shown in Fig. 1) create an anti-flow movement of particles, which promotes the uniform distribution of components in the substrate. Rack 8 is adjustable so that one could change the height of fixing the support of drum 5 in the reactor. A given structure makes it possible to change the angle of inclination of the axis of drum rotation in the range from 0 to 20 degrees relative to the horizontal surface. Adjusting the inclination angle is discrete in increments of 5 degrees. Owing to this technique, a substrate could be moved along drum 5 , which additionally performs its mixing during composting. The total weight of the installation in an unloaded condition is $92 \mathrm{~kg}$, the drum radius is $275 \mathrm{~mm}$, the drum length is $70 \mathrm{~mm}$.

The substrate consisted of $50 \%$ of the mixture of litter manure and straw chips (with a total humidity of $45 \%$ ), $20 \%$ of bird droppings, and $30 \%$ of plant materials (15\% peat, $15 \%$ sawdust of hardwood trees). To ensure the self-heating process of fermentation of the substrate, it was periodically agitated with a simultaneous supply of air for aeration. The substrate was stirred every 55 minutes, and the stirring time was 5 minutes. The performance of the air supply system is adjusted so that, in the event of failure of the check valve in loading hatch 6 of drum 5, the ratio of air to substrate was 4:1.

Granules of red polyphenylsulfide with a particle diameter of $1.5 \mathrm{~mm}$ were used as a control component; that corresponds to the particle size interval of the substrate components. The density of polyphenylsulfide granules was equal to the density of the substrate and amounted to $300-360 \mathrm{~kg} / \mathrm{m}^{3}$.

Samples of the mixed substrate components were selected by a tubular sampler at different points of the drum at the removed lid at each of the composting stages. The humidity of the substrate was measured by the ZD-05 device (Japan). The weight of the sample was determined by the laboratory scales FEH-320 («Ukrvagy», Ukraine). The temperature of the substrate was measured by the temperature sensor TSP 1-8 (PAT «Tera», Ukraine). The reactor's drum frequency rotation was measured by a portable optical tachometer testo 465 (Germany).

In order to establish the dependence of the coefficient of friction of substrate particles on the steel surface of the drum blades on the humidity of the substrate and the movement speed of its particles, we used a procedure reported in [28]. The results from our experimental study were treated using the software packages Microsoft Excel 2003 and Statistica 11.0 (StatSoft, USA).

\section{Results of studying the parameters of a drum-type reactor}

5. 1. The simulation of reactor parameters and the substrate's components mixing process parameters

In accordance with the geometric parameters and the accepted scheme of reactor operation, the substrate particles inside the drum consistently undergo the following stages of movement. At the beginning of the movement, the substrate particles move in the direction of the drum movement. Then there is the rolling of particles on the free surface of the rising substrate material. The next stage is the movement of particles on the radial blade after it exits the substrate-filled drum, followed by the free fall of particles after descending from the blades. Agitation is enabled within the entire confined drum space. However, depending on the location of each individual particle of the material at a certain point in time, it has different trajectories of movement.

The presence of radially fixed blades on the working surface of the drum improves the retention of substrate particles in the raised zone, expands the working area of agitation by intensifying the space above the rolling surface, and prevents their slipping. In order to increase surface flows in the free space of the drum, we set the angle of inclination and width of the blade that would ensure the complete descent of the substrate particles. With incomplete descent, the substrate particles do not dissipate in the free space of the drum but return to the common flow, which impairs their redistribution.

In order for the components to be evenly distributed over the surface of the substrate blockage by the falling flow, it is necessary that the particles that descend from the radial blade last should, at the point of contact with the drum shell, reach the boundary of the blockage (Fig. 2). This condition is met under certain kinematic parameters.

The source data for mathematical modeling are the physicochemical properties of the substrate, the geometric parameters of the free space of the drum, and the boundaries of scattering of substrate particles in free space under which the best conditions for the agitation of substrate components are provided. The substrate is a complex environment that consists of particles of different components, each with its own geometric parameters. The geometry of each individual particle during modeling would not be considered. The substrate environment solidity hypothesis [29] would be applied, allowing the state of this environment to be described by volume and continuously space-distributed characteristics. This would significantly simplify the mathematical model without reducing the degree of its reliability. 

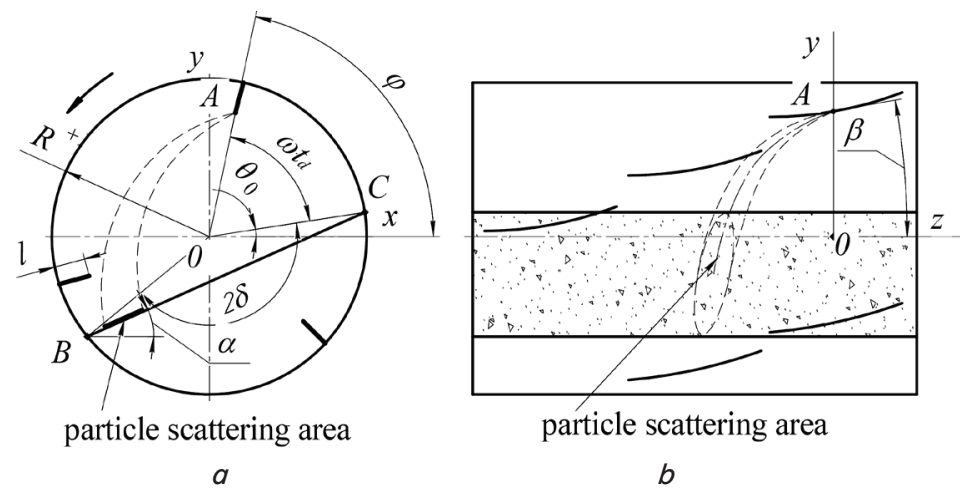

particle scattering area

b

Fig. 2. Trajectories of substrate particles when falling from a curved radially installed blade:

$a-$ transverse section; $b$ - longitudinal section; $x, y, z$ - axes of the drum; $\beta$ - angle of inclination of the blade to the $z$ axis of the drum, rad; $\varphi-$ angle of rotation of the blade relative to the $x$ axis, rad; $R-$ drum radius, m; / - the width of the blade, $\mathrm{m} ; \omega$ - angular velocity of the drum, rad $/ \mathrm{s} ; \theta_{0}$ - the initial angle of the blade exit from the substrate, rad; $2 \delta$ - the central angle of the substrate material segment, rad; $\alpha$ - the angle of inclination of the surface layer of the substrate to the $x$ axis, rad; $\omega \cdot t_{d}-$ substrate transportation angle

The purpose of mathematical modeling is to establish a link between the structural parameters of the drum, the kinematic parameters of particle movement, and the physicochemical properties of the substrate. This relation could be expressed by changing the nature of the process of rubbing particles of the substrate, moving in the drum, on radial blades. Consequently, our modeling includes the following steps to determine:

- the linear movement speed of substrate particles on the surface of the blade;

- the optimal kinematic parameters of the process of mixing substrate particles, provided they are scattered in the longitude and transverse cross-sections.

Knowing the angular velocity of the drum rotation and the speed that a substrate particle acquires when descending from a blade, we determine the initial speed of the substrate material during a free fall in the unfilled drum space. To determine the radial speed of movement of a conditional particle on the curved surface of the blade, we use the following estimation scheme (Fig. 3).

To determine the radial speed of a substrate particle, we build an equation of its relative movement in the plane of the cross-section:

$$
m a_{A}=\overline{F_{f}}+\overline{F_{a}}+\overline{F_{C}},
$$

where $a_{A}$ is the complete acceleration of a substrate particle at point $\mathrm{A}, \mathrm{m} / \mathrm{s}^{2}$.

Fig. 3 shows the inner edge of the radial blade and the force model at point A to which the polar coordinate system is tied. The curved surface of the blade is described by the following equation:

$$
r=a^{\varphi}
$$

where $a$ is the curvature parameter. Taking into consideration the data reported in work [12], as well as equation (2), we derived the final equation that describes the movement of substrate particles along the surface of the blade:

$$
\frac{\mathrm{d}^{2} r}{\mathrm{~d} t^{2}}-\left(\left(\frac{\mathrm{d} r}{\mathrm{~d} t}\right)^{2} / r(\ln a)^{2}\right)=2 \omega\left(\frac{\mathrm{d} r}{\mathrm{~d} t} / \ln a\right)-2 f \omega \frac{\mathrm{d} r}{\mathrm{~d} t},
$$

where $f$ is the coefficient of friction of substrate particles on the surface of the blade.

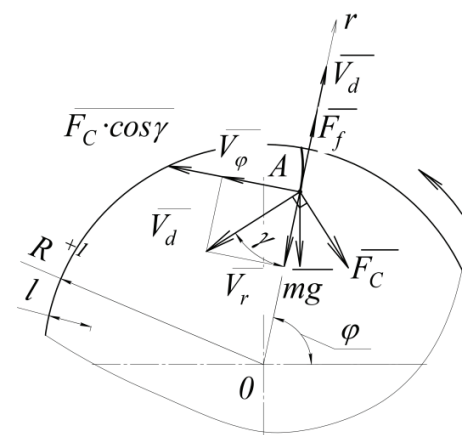

Fig. 3. Estimation scheme of movement of the conditional particle of the substrate on the curved surface of the drum blade: $R$ - drum radius, $\mathrm{m}$; $/$ - the width of the blade, $\mathrm{m}$; $\omega$-drum's angular velocity, $\mathrm{rad} / \mathrm{s} ; V_{d}-$ the relative speed of a conditional substrate particle, $\mathrm{m} / \mathrm{s} ; V_{r}-$ the radial speed of substrate particles on a blade, $\mathrm{m} / \mathrm{s} ; V_{\varphi}-$ the tangential speed of substrate particles on a blade, $\mathrm{m} / \mathrm{s} ; F_{f}-$ the friction force of a substrate particle on the surface of the blade, $\mathrm{N} ; F_{a}$ and $F_{C}$ - respectively, the portable force of inertia and the force of inertia from the Coriolis acceleration, $\mathrm{N} ; F_{C} \cdot \cos \gamma-$ normal reaction, $N ; \varphi-$ angle of rotation of the blade relative to the $x$ axis, rad; $\gamma-$ angle of inclination of the vector of the substrate particle speed relative to radial speed, rad; $g-$ free fall acceleration, $\mathrm{m} / \mathrm{s}^{2} ; m-$ a substrate particle weight, $\mathrm{kg}$

Since the speed of the substrate particles is linear and insignificant, the friction coefficient is determined using a classical theory [30] from the following dependence:

$$
f=b \cdot V
$$

where $b$ is a dimensionless coefficient; $V$ is the speed of substrate particles on the surface of the blade, $\mathrm{m} / \mathrm{s}$.

After analyzing the dependences set out in [30], it is necessary to further experimentally determine the dependence of the coefficient of friction of substrate particles on the material of blades (structural steel), not only on speed but also on the humidity of the substrate. This experiment was conducted in accordance with [28]. The experimental data obtained, following the statistical treatment using the Statistica 11.0 software package (StatSoft, USA), were used to find the approximation coefficients $k_{1}, k_{2}, k_{3}$. 
Based on the results from experimental studies, we have derived approximation dependence (5) and the response surface (Fig. 4) for the dependence of the friction coefficient $f$ of particles on the surface of the blade on the substrate humidity $W$ and the radial component of the linear speed $V_{r}$ of the movement of substrate particles:

$$
f=k_{1} V_{r}+k_{2}(W-57)^{2}+k_{3},
$$

where $k_{1}, k_{2}$, and $k_{3}$ are the estimated coefficients $\left(k_{1}=0.047\right.$, $k_{2}=0.0009$, and $\left.k_{3}=0.27\right) ; W$ is the substrate humidity, $\%$.

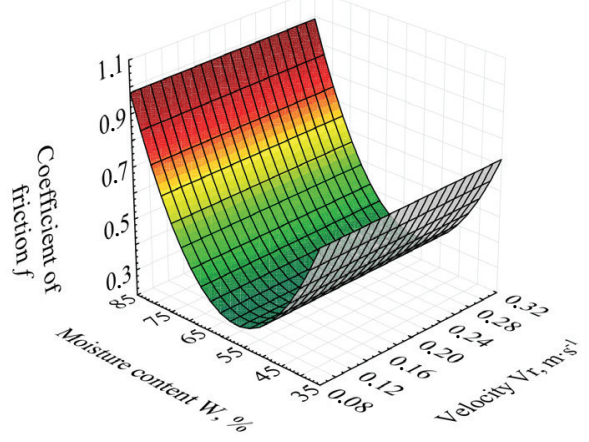

Fig. 4. Dependence of the coefficient of friction of substrate particles on the surface of the blade on the moisture content of the substrate and the speed of movement of substrate particles

One of the conditions for uniform mixing of the substrate is the lack of blocking its particles on the blades. The condition for the absence of blocking is as follows:

$$
\overline{F_{f}} \leq \overline{F_{a}}+\overline{F_{C}} .
$$

Based on the condition $\overline{F_{C}} \perp V_{d}$, and knowing the $V_{d}$ value, we obtain the equation for the condition of the absence of substrate particles' blocking on the blade:

$$
\overline{F_{f}} \leq \overline{F_{a}} \cdot \cos \gamma .
$$

The friction force is determined as follows:

$$
\overline{F_{f}}=f \cdot \overline{F_{C}} \cdot \cos \gamma=\overline{F_{C}} \cdot \cos \gamma \cdot\left(k_{1} V_{r}+k_{2}(W-57)^{2}+k_{3}\right),
$$

In turn, the speeds $V_{\varphi}, V_{r}$, and cos $\gamma$ are calculated as follows:

$$
\begin{aligned}
& V_{\varphi}=r \frac{\mathrm{d} \varphi}{\mathrm{d} t} ; \quad V_{r}=\frac{\mathrm{d} r}{\mathrm{~d} t} \\
& \cos \gamma=\left(\frac{\mathrm{d} r}{\mathrm{~d} t}\right) /\left(\sqrt{\left(\frac{\mathrm{d} r}{\mathrm{~d} t}\right)^{2}+\left(r \cdot \frac{\mathrm{d} \varphi}{\mathrm{d} t}\right)^{2}}\right) .
\end{aligned}
$$

Following the mathematical transforms using expression (9) and (10), we obtain:

$$
\begin{aligned}
& \overline{F_{C}} \cdot \cos \gamma=2 m \omega \sqrt{\left(\frac{\mathrm{d} r}{\mathrm{~d} t}\right)^{2}+\left(r \cdot \frac{\mathrm{d} \varphi}{\mathrm{d} t}\right)^{2}} \times \\
& \times\left(\frac{\mathrm{d} r}{\mathrm{~d} t} / \sqrt{\left(\frac{\mathrm{d} r}{\mathrm{~d} t}\right)^{2}+\left(r \cdot \frac{\mathrm{d} \varphi}{\mathrm{d} t}\right)^{2}}\right)=2 m \omega \frac{\mathrm{d} r}{\mathrm{~d} t} .
\end{aligned}
$$

Consequently, taking into consideration equation (10), the condition for the absence of substrate particles' blocking on the drum blade during an agitation process takes the following form:

$$
\begin{aligned}
& 2 m \omega \cdot f \frac{\mathrm{d} r}{\mathrm{~d} t} \leq m \omega^{2} r \cdot \cos \gamma \\
& 2 m \omega \cdot\left(k_{1} V_{r}+k_{2}(W-57)^{2}+k_{3}\right) \frac{\mathrm{d} r}{\mathrm{~d} t} \leq m \omega^{2} r \times \\
& \times\left(\frac{\mathrm{d} r}{\mathrm{~d} t} / \sqrt{\left(\frac{d r}{d t}\right)^{2}+\left(r \cdot \frac{d \varphi}{d t}\right)^{2}}\right) .
\end{aligned}
$$

Since $r(\mathrm{~d} \varphi / \mathrm{d} t)=(\mathrm{d} r / \mathrm{d} \varphi) / \ln a$, we obtain:

$$
\begin{aligned}
& 2\left(k_{1} \frac{\mathrm{d} r}{\mathrm{~d} t}++k_{2}(W-57)^{2}+k_{3}\right) \frac{\mathrm{d} r}{\mathrm{~d} t} \leq \omega \cdot r \times \\
& \times\left(\frac{\mathrm{d} r}{\mathrm{~d} t}\right) / \sqrt{\left(\frac{\mathrm{d} r}{\mathrm{~d} t}\right)^{2}+\left(r \cdot \frac{\mathrm{d} r}{\mathrm{~d} t} / \ln a\right)^{2}} .
\end{aligned}
$$

Following a series of transforms to equation (12), we obtain a condition for limiting the speed of substrate particles under which the process of blocking substrate particles on the blades would not occur:

$$
\frac{d r}{d t} \leq \omega r /\left[2\left(k_{1} \frac{\mathrm{d} r}{\mathrm{~d} t}+k_{2}(W-57)^{2}+k_{3}\right) \sqrt{1+(r / \ln a)^{2}}\right] .
$$

In equation (13), $\mathrm{d} r / \mathrm{d} t=V_{r}$ is the radial movement speed of substrate particles on a blade calculated in the cross-section.

The model also limits a value of the maximum permissible angular velocity of the drum $\omega$ at which the uniform agitation of substrate particles throughout the entire volume would occur.

On the other hand, the value of the minimum angular velocity of the drum is limited by the condition of the maximum scattering of substrate particles descending from the blade when the drum is rotating.

Fig. 2 shows that particles of the substrate, due to the radial shape of the blade during the descent on its surface, move along three coordinates $-x, y$, and $z$. At the same time, a scattering field is formed of the material descending from the blade at point A. The scattering field is in the plane formed by the surface of blocking inside the drum. According to the laws of kinematics, the trajectory of a substrate's particle movement during the fall could be represented by the parabola equation:

$$
\left\{\begin{array}{l}
x=(R-l) \cos \varphi-V_{0} t \cos \gamma_{0} ; \\
y=(R-l) \sin \varphi-V_{0} t \sin \gamma_{0}-g t^{2} / 2, \\
z=-V_{0} t \cos \beta
\end{array}\right.
$$

where $x, y, z$ are the coordinates of the substrate particle position along the flight trajectory, $\mathrm{m} ; V_{0}$ is the absolute value of the initial speed of movement of the substrate particle when descending from the blade, $\mathrm{m} / \mathrm{s} ; \gamma_{0}$ is the initial angle of inclination of the vector of the substrate particle speed to the $x$ axis during a flight, rad; $g$ is the free fall acceleration, $\mathrm{m} / \mathrm{s}^{2}$; $t$ is the current flight time of the substrate particle, s.

The surface of a substrate's particle blocking in the drum could be conditionally taken as a plane, and, in the cross- 
section, as a chord of the segment with a sector angle of $2 \delta$. Under these conditions, equation (14) takes the following form:

$$
y=x \cdot \operatorname{tg} \alpha-R \frac{\cos \delta}{\cos \alpha} .
$$

Based on the geometric parameters of the cross-section of the drum, one could find the following:

$$
\begin{aligned}
& V_{0} \cdot t=S=((R-l) \cos \varphi-x) / \cos \gamma_{0} ; \\
& t=S / V_{0}=((R-l) \cos \varphi-x) /\left(V_{0} \cdot \cos \gamma_{0}\right) .
\end{aligned}
$$

To formulate the conditions for the most effective scattering of substrate particles in the cross-section of the drum, when rotating a drum blade, consider Fig. 2. Optimal conditions are those when, during descending from the blade, the first particles of the substrate begin to fall as close as possible to the upper boundary of the blocking, while the last reach, when falling, the lower part of the blockage. In turn, this contributes to the sufficient aeration of particles during descent and the even agitation of substrate components.

Thus, the optimal angular velocity of drum rotation is determined by solving a system of equations. The system of equations includes the equation of the descent of substrate particles along a parabolic trajectory and the equation of the substrate particle blockage surface in the drum:

$$
\left\{\begin{array}{l}
y=(R-l) \sin \varphi-\frac{(R-l) \cos \varphi-x}{\cos \gamma_{0}} \sin \gamma_{0}- \\
-\frac{g}{2}\left(\frac{(R-l) \cos \varphi-x}{V_{0} \cos \gamma_{0}}\right)^{2} \\
y=x \operatorname{tg} \alpha-R \cdot \cos \delta / \cos \alpha \\
R^{2}=x^{2}+y^{2}
\end{array}\right.
$$

The coordinates of the intersection point of the circle describing the cross-section of the drum and the surface of the substrate particle blockage in the drum are found from the equation system (17):

$$
\begin{aligned}
& R^{2}\left(1-\cos ^{2} \delta / \cos ^{2} \alpha\right)= \\
& =x^{2}+x^{2} \operatorname{tg}^{2} \alpha-2 \cdot x \cdot \operatorname{tg} \alpha \cdot R(\cos \delta / \cos \alpha) .
\end{aligned}
$$

Hence:

$$
x_{1,2}=R \sin \alpha \cos \delta \pm R \cos \alpha \sin \delta .
$$

$\left\{\begin{array}{l}y_{1}^{2}=R^{2}-x_{1}^{2}=R^{2}\left[1-\sin ^{2}(\alpha+\delta)\right]=R^{2} \cos ^{2}(\alpha+\delta) ; \\ y_{2}^{2}=R^{2}-x_{2}^{2}=R^{2}\left[1-\sin ^{2}(\alpha-\delta)\right]=R^{2} \cos ^{2}(\alpha-\delta) .\end{array}\right.$

$$
\left\{\begin{array}{l}
y_{1}=R \cos (\alpha+\delta) \\
y_{2}=R \cos (\alpha-\delta)
\end{array}\right.
$$

A solution corresponding to the graphical representation of the process shown in Fig. 2 takes the following form:

$$
\left\{\begin{array}{l}
x_{2}=-R \sin (\delta-\alpha) \\
y_{2}=-R \cos (\delta-\alpha)
\end{array}\right.
$$

By fitting the resulting values of $x_{2}$ and $y_{2}$ in the parabola equation, we obtain:

$$
\begin{aligned}
& -R \cos (\delta-\alpha)= \\
& =(R-l) \sin \varphi-\frac{(R-l) \cos \varphi+R \sin (\delta-\alpha)}{\cos \gamma_{0}} \sin \gamma_{0}- \\
& -\frac{g}{2}\left(\frac{(R-l) \cos \varphi+R \sin (\delta-\alpha)}{V_{0} \cos \gamma_{0}}\right)^{2},
\end{aligned}
$$

where $\gamma_{0}$ is the smallest angle of inclination of the blade to the $x$ axis of the drum at in which the substrate particles begin to descent into the plane of the blockage. That is, the friction coefficient is $f=\operatorname{tg} \gamma_{0}$.

The drum radius $R$, the blade width $l$, the central angle of the material segment in the drum $2 \delta$, and the inclination angle $\alpha$ of the substrate's surface layer to the $x$ axis should be considered constant and unchangeable within this study. Having determined the angle $\varphi$ of the blade rotation relative to the $x$ axis, the initial angle of inclination of the substrate particle speed vector to the $x$ axis during a flight $\gamma_{0}$, and the initial flight speed of the substrate particle when descending from the blade, we obtain an equation to determine the optimal speed:

$$
\begin{aligned}
& (R-l) \sin \left(\theta_{0}+\omega t_{d}\right)+R \cos (\delta-\alpha)- \\
& -\left[(R-l) \cos \left(\theta_{0}+\omega t_{d}\right)+R \sin (\delta-\alpha)\right] \times \\
& \times\left(k_{1} V_{R}+k_{2}(W-57)^{2}+k_{3}\right)- \\
& -\frac{g}{2}\left(\frac{(R-l) \cos \left(\theta_{0}+\omega t_{d}\right)+R \sin (\delta-\alpha)}{\sqrt{\omega^{2}(R-l)^{2}+V_{R}^{2}} \cdot \cos \left(\operatorname{arctg}\left(\begin{array}{l}
k_{1} V_{R}+k_{2} \times \\
\times(W-57)^{2}+k_{3}
\end{array}\right)\right)}\right)^{2}=0,
\end{aligned}
$$

where

$$
\begin{aligned}
& \varphi=\theta_{0}+\omega t_{d} ; \\
& \gamma_{0}=\omega t+\theta_{0}=\operatorname{arctg}(f)=\operatorname{arctg}\left(k_{1} V_{R}+k_{2}(W-57)^{2}+k_{3}\right) .
\end{aligned}
$$

The resulting dependences indicate that the degree of uniformity in scattering the substrate particles when descending from the drum blade depends on the angular velocity of the drum and the moisture content of the compostable substrate.

Introduce variables to simplify the perception of the following equation:

$$
\left\{\begin{array}{l}
\lambda_{1}=(R-l) \sin \left(\theta_{0}+\omega t_{d}\right)+R \cos (\delta-\alpha) ; \\
\lambda_{2}=\omega^{2} \cdot(R-l)^{2} \\
\lambda_{3}=(R-l) \cos \left(\theta_{0}+\omega t_{d}\right)+R \sin (\delta-\alpha) ; \\
\lambda_{4}=k_{2}(W-57)^{2}+k_{3} .
\end{array}\right.
$$

We obtain the expression:

$$
\begin{aligned}
& \lambda_{1}-\lambda_{3}\left(k_{1} V_{R}+\lambda_{4}\right)- \\
& -\frac{g}{2}\left(\frac{\lambda_{3}}{\sqrt{\lambda_{2}+V_{R}^{2}} \cos \left(\operatorname{arctg}\left(k_{1} V_{R}+\lambda_{4}\right)\right)}\right)^{2}=0 .
\end{aligned}
$$

Equation (26) was solved in the Mathcad 6.0 programming environment (Mathsoft, PTC, USA) by expanding a complex function into a series. 


$$
\lambda_{1}-\lambda_{3} \cdot \lambda_{4}-\frac{g \lambda_{3}^{2} \cdot\left(\lambda_{4}^{2}+1\right)}{2 \lambda_{2}}-V \cdot\left(k_{1} \cdot \lambda_{3}+\frac{g k_{1} \lambda_{3}^{2} \cdot \lambda_{5}}{\lambda_{2}}\right)=0
$$

The programmable error of expanding a function into a series does not exceed $1.5 \%$ and could be compared to the experiment's error.

A solution to equation (27) is the following mathematical notation:

$$
V=\frac{\left(\lambda_{1}-\lambda_{3} \cdot \lambda_{4}-\frac{g \lambda_{3}^{2} \cdot\left(\lambda_{4}^{2}+1\right)}{2 \lambda_{2}}\right)}{\left(k_{1} \cdot \lambda_{3}+\frac{g k_{1} \lambda_{3}^{2} \cdot \lambda_{4}}{\lambda_{2}}\right)} .
$$

The result of solving mathematical equations (13) and (28) is:
If one adjusts general equation (29) to the parameters of the experimental installation and the studied composition of the substrate, by fitting known parameters, we obtain a dependence to determine the optimal speed of agitating the substrate particles in the reactor's drum:

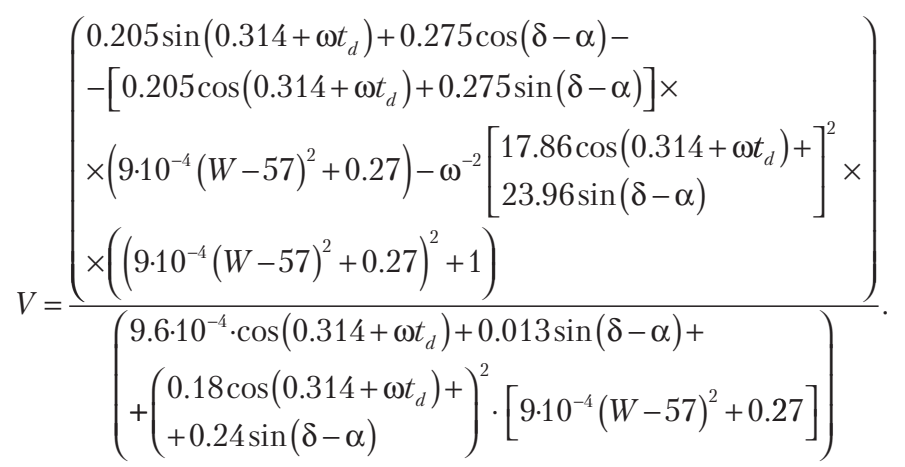

$$
V=\frac{\left(\begin{array}{l}
(R-l) \sin \left(\theta_{0}+\omega t_{d}\right)+R \cos (\delta-\alpha)-\left[(R-l) \cos \left(\theta_{0}+\omega t_{d}\right)+R \sin (\delta-\alpha)\right] \times \\
\left.\times\left(k_{2}(W-57)^{2}+k_{3}\right)-g\left[(R-l) \cos \left(\theta_{0}+\omega t_{d}\right)+R \sin (\delta-\alpha)\right]^{2} \times \frac{\left(\left(k_{2}(W-57)^{2}+k_{3}\right)^{2}+1\right)}{2 \omega^{2} \cdot(R-1)^{2}}\right)
\end{array}\right.}{k_{1} \cdot\left((R-l) \cos \left(\theta_{0}+\omega t_{d}\right)+R \sin (\delta-\alpha)\right)+\frac{g k_{1}\left(\begin{array}{l}
\left.(R-l) \cos \left(\theta_{0}+\omega t_{d}\right)+\right)^{2} \\
+R \sin (\delta-\alpha)
\end{array}\right)^{2} \cdot\left[k_{2}(W-57)^{2}+k_{3}\right]}{\omega^{2} \cdot(R-1)^{2}}}
$$

The resulting expression makes it possible to accurately enough assess the speed of substrate movement over the blade at which there is the most uniform distribution of the components in the substrate depending on its moisture content and the drum's geometry.

where $t_{d}$ is the time of rotating the drum from the moment the blade exits the substrate to its full unloading from the particles of the substrate, s. According to equation (13), the coordinates of the substrate particle position at the time of descending from the drum blade are determined by its radial speed of movement on the blade at the time of descent $V_{R}(R-l)$. That makes it possible to determine the absolute speed of the particle $V_{o}$ and the initial angle of inclination of the vector of absolute particle flight speed to the horizon $\gamma_{0}$.

Based on equation (29), we can conclude that the uniformity of mixing, which is determined by the uniformity of the distribution of the substrate falling from the blade over the surface of the blockage, depends on the angular velocity and moisture content of the raw material.
5. 2. Experimental study of the impact of reactor parameters on the mixing process

To confirm the results from theoretical calculations, we have experimentally established the influence of angular velocity on the process of mixing the substrate components in the reactor's drum (Table 1).

The dependence of the linear movement speed of substrate particles on a blade on the angular velocity of the drum, taking into consideration the angle of the substrate material blocking in the drum, is shown in Fig. 5.

\begin{tabular}{|c|c|c|c|c|c|c|}
\hline \multirow{3}{*}{$\begin{array}{c}\text { Experi- } \\
\text { ment No. }\end{array}$} & \multirow{3}{*}{$\begin{array}{c}\text { The inclination angle } \\
\text { of a substrate's surface layer to } \\
\text { the } x \text { axis, } \alpha \text {, degree }\end{array}$} & \multirow{3}{*}{$\begin{array}{c}\text { The central angle of } \\
\text { a substrate's material segment } \\
2 \delta \text {, degree }\end{array}$} & \multirow{3}{*}{$\begin{array}{l}\text { Substrate transportation } \\
\text { angle } \omega \cdot t_{d} \text {, degree }\end{array}$} & \multicolumn{3}{|c|}{ Drum angular velocity $\omega, \mathrm{rad} / \mathrm{s}$} \\
\hline & & & & 0.524 & 1.047 & 1.571 \\
\hline & & & & \multicolumn{3}{|c|}{ Speed $V, \mathrm{~m} / \mathrm{s}$} \\
\hline \multirow{4}{*}{1} & \multirow{4}{*}{12} & \multirow{4}{*}{155} & \multirow{4}{*}{110} & \multicolumn{3}{|c|}{ Theoretical values } \\
\hline & & & & -4.98 & 1.67 & 3.02 \\
\hline & & & & \multicolumn{3}{|c|}{ Experimental data } \\
\hline & & & & 0 & 1.59 & 3.18 \\
\hline \multirow{4}{*}{2} & \multirow{4}{*}{24} & \multirow{4}{*}{140} & \multirow{4}{*}{90} & \multicolumn{3}{|c|}{ Theoretical values } \\
\hline & & & & -4.43 & 2.81 & 4.29 \\
\hline & & & & \multicolumn{3}{|c|}{ Experimental data } \\
\hline & & & & 0 & 2.9 & 4.39 \\
\hline \multirow{4}{*}{3} & \multirow{4}{*}{36} & \multirow{4}{*}{125} & \multirow{4}{*}{70} & \multicolumn{3}{|c|}{ Theoretical values } \\
\hline & & & & -2.98 & 4.14 & 5.60 \\
\hline & & & & \multicolumn{3}{|c|}{ Experimental data } \\
\hline & & & & 0 & 4.18 & 5.47 \\
\hline
\end{tabular}

Table 1

Dependence of the movement speed of a substrate particle on the blade on the drum's angular velocity at a substrate moisture content of $W=60 \%$ 


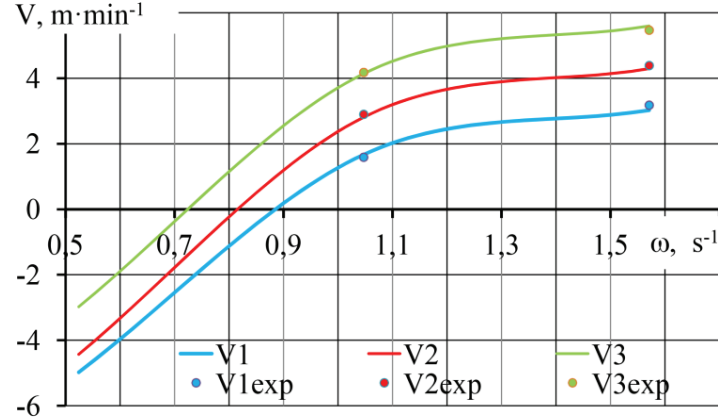

Fig. 5. Dependence of the linear speed of substrate particles on a blade's curved surface on the drum angular velocity

The purpose of our experimental study was to confirm the adequacy of the constructed mathematical model. Therefore, the data on the natural experiment (Fig. 5, points $V_{\text {1exp }}, V_{\text {2exp }}$, $\left.V_{3 \exp }\right)$ were compared to the data from the estimation experiment (Fig. 5, points on curves $V_{1}, V_{2}, V_{3}$ ). That is, the data from the natural experiment were compared with the numerical values of the substrate's movement speed on blades, derived by fitting the conditions of the natural experiment into mathematical equation (30). To verify the model's compliance with the experimental results, we used a procedure reported in [31]. The hypothesis about the adequacy of the model of the examined object was checked according to the index of determination. The level of deviation of theoretical data obtained from experimental data in terms of the determination index is $\eta^{2}=0.99$, which indicates the adequacy of the constructed mathematical model.

We have experimentally established the dependence of the linear movement speed of substrate particles over a blade's curved surface on the substrate's moisture content (Table 2).

The dependence of the movement speed of a substrate's particle over a radial blade on the substrate's moisture content is shown in Fig. 6.

To verify the reliability of model (30) based on the experiment's results, we applied a procedure reported in [31]. The hypothesis about the adequacy of the model of the examined object was checked according to the index of determination. The level of deviation of theoretical data from experimental data in terms of the determination index is $\eta^{2}=0.99$, which indicates the adequacy of the constructed mathematical model.

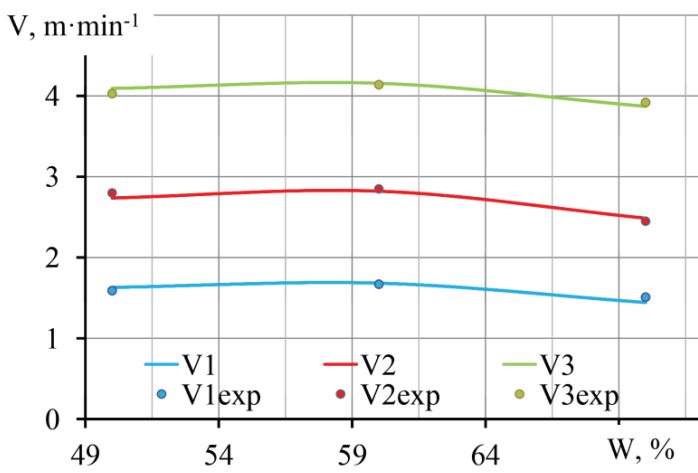

Fig. 6. Dependence of the linear movement speed of substrate particles over a blade's curved surface on the substrate's moisture content

Fig. 6 shows that the recommended angular velocity of a reactor's drum is $\omega=0.93 \ldots 1.18 \mathrm{rad} / \mathrm{s}(n=8.5 \ldots 11.3 \mathrm{rpm})$, and the substrate's moisture content is $W=57 . .62 \%$.

\section{Discussion of results of studying the impact of reactor parameters on the mixing process}

The result of our study has established for all cases (Fig. 5) that a change in the angle of the material's blocking in a drum changes the movement speed of substrate particles according to a similar trend. Fig. 5 shows that for experiments No. 1, No. 2, and No. 3 , at the drum's angular velocity values of $\omega=0.5 \ldots . .89 \mathrm{rad} / \mathrm{s}$, $\omega=0.5 \ldots 0.81 \mathrm{rad} / \mathrm{s}$, and $\omega=0.5 \ldots 0.72 \mathrm{rad} / \mathrm{s}$, respectively, the theoretical movement speed of substrate particles over the drum blades is negative. When conducting our experimental study at the specified values of the drum's angular velocity, the measuring equipment recorded the movement speed of substrate particles over the drum blades equal to zero. This indicates that in the range of angular velocities $\omega=0.5 \ldots 0.89 \mathrm{rad} / \mathrm{s}$, the vector of substrate particle speed is directed to the drum walls. This movement contributes to blocking the substrate particles on the inner surface of the drum, thus preventing the agitation.

Increasing the drum's angular velocity leads to an increase in the movement speed of substrate particles over the blades. The processes of diffusion and convective mixing begin to prevail, which, unlike the segregation process, increases the uniformity of particle dispersal in the substrate.

Table 2

Dependence of the movement speed of a substrate's particle over a radial blade on the substrate's moisture content at a value of the drum's angular velocity of $\omega=1.05 \mathrm{rad} / \mathrm{s}$

\begin{tabular}{|c|c|c|c|c|c|c|}
\hline \multirow{3}{*}{$\begin{array}{l}\text { Experi- } \\
\text { ment No. }\end{array}$} & \multirow{3}{*}{$\begin{array}{c}\text { The inclination angle of } \\
\text { a substrate's surface layer to } \\
\text { the } x \text { axis, } \alpha \text {, degree }\end{array}$} & \multirow{3}{*}{$\begin{array}{c}\text { The central angle of } \\
\text { a substrate's material segment } \\
2 \delta \text {, degree }\end{array}$} & \multirow{3}{*}{$\begin{array}{l}\text { Substrate transportation } \\
\text { angle } \omega \cdot t_{d} \text {, degree }\end{array}$} & \multicolumn{3}{|c|}{ Substrate moisture content $W, \%$} \\
\hline & & & & 50 & 60 & 70 \\
\hline & & & & \multicolumn{3}{|c|}{ Speed $V, \mathrm{~m} / \mathrm{d}$} \\
\hline \multirow{4}{*}{1} & \multirow{4}{*}{12} & \multirow{4}{*}{155} & \multirow{4}{*}{110} & \multicolumn{3}{|c|}{ Theoretical values } \\
\hline & & & & 1.63 & 1.68 & 1.44 \\
\hline & & & & \multicolumn{3}{|c|}{ Experimental data } \\
\hline & & & & 1.59 & 1.67 & 1.51 \\
\hline \multirow{4}{*}{2} & \multirow{4}{*}{24} & \multirow{4}{*}{140} & \multirow{4}{*}{90} & \multicolumn{3}{|c|}{ Theoretical values } \\
\hline & & & & 2.74 & 2.82 & 2.49 \\
\hline & & & & \multicolumn{3}{|c|}{ Experimental data } \\
\hline & & & & 2.8 & 2.85 & 2.45 \\
\hline \multirow{4}{*}{3} & \multirow{4}{*}{36} & \multirow{4}{*}{125} & \multirow{4}{*}{70} & \multicolumn{3}{|c|}{ Theoretical values } \\
\hline & & & & 4.09 & 4.16 & 3.87 \\
\hline & & & & \multicolumn{3}{|c|}{ Experimental data } \\
\hline & & & & 4.03 & 4.14 & 3.92 \\
\hline
\end{tabular}


Optimal is the range of values of the drum's angular velocity equal to $\omega=0.93 \ldots 1.18 \mathrm{rad} / \mathrm{s}(n=8.5 \ldots 11.3 \mathrm{rpm})$. This range is determined by the conditions for the maximum and minimum speed of movement of particles over a blade, represented by dependences (13) and (30), and shown in Fig. 5.

In a given range, we observed the highest mixing quality of substrate components, which was evaluated by the content of the control component in the substrate. The content of the control component in the substrate was $3 \%$ of the total mass of the material in the chamber. According to earlier studies [8], the smallest value of the coefficient of variation of the actual distribution of the control component in samples was $11.4 \%$ at the drum's frequency of rotation equal to $\omega=1.05 \mathrm{rad} / \mathrm{s}$.

Fig. 6 shows that in the first experiment an increase in the substrate's moisture content from $50 \%$ to $56 \%$ increases the movement speed of substrate particles from 1.6 to 1.67. In the second and third experiments, the movement speed of substrate particles increases from 2.7 to $2.85 \mathrm{~m} / \mathrm{s}$, and from 4 to 4.16 , respectively. This phenomenon is explained by a decrease in the friction coefficient of substrate particles on the surface of a radially installed curved blade with an increase in the substrate's moisture content to $61 \%$ (Fig. 4). The friction coefficient at an increase in the substrate's moisture content from 40 to $61 \%$ decreases from 0.544 to 0.28 . With the further increase in the substrate's moisture content to values above $61 \%$ (Fig. 4), there is an increase in the friction coefficient to a value of 0.76 (at a substrate's moisture content of $80 \%$ ). In this case, the velocity of substrate particles on the surfaces of the blades decreases (Fig. 6). As a result of reducing the movement speed of substrate particles, they stick to the surface of the blades and other elements of a drum's structures, the quality of agitation deteriorates. This is evidenced by the increase in the smallest value of the coefficient of variance of the actual distribution of the control component in samples to $22.78 \%$, according to study [8], which, in turn, worsens the conditions of the substrate composting process.

The application of the mathematical model and the results of our experimental study would make it possible, at the level of an estimation experiment, to determine the optimal movement speed of substrate particles on a blade when changing the manufacturing parameters of the mixing process and the substrate's physical-chemical properties. This could significantly reduce the cost of physical experiments.
Further research will address establishing the optimal values of parameters and operational modes of the reactor at which the minimum energy intensity of the process of mixing substrate components is achieved while ensuring high-quality compost in terms of biotechnological indicators.

\section{Conclusions}

1. We have built a mathematical model that incorporates equations to determine the following:

- the linear movement speed of substrate particles on the surface of the blade;

- the optimal kinematic parameters of the process of mixing the particles of substrate components, provided particles are dispersed in the cross-section;

- the optimal kinematic parameters of the process of mixing the particles of substrate components, provided particles are dispersed in the longitudinal section.

The derived solution to the differential equation of rotation of the drum mixer when agitating the substrate establishes the relationship between the manufacturing and structural parameters of the mixer and the substrate's physical-chemical properties. The model constructed makes it possible to establish the dependence of the magnitude of the linear movement speed of substrate particles on the surface of the blade under which there is a complete dispersion of the material on the free surface of the substrate's segment on the substrate's moisture content and the drum's angular velocity.

2. Experimentally, it has been established that the complete scattering of substrate components on the free surface of a working segment would occur at the substrate's moisture content of $57 . . .62 \%$ and the drum's angular velocity within $0.93 \ldots 1.18 \mathrm{~s}^{-1}(n=8.5 \ldots 11.3 \mathrm{rpm})$.

3 . The adequacy of the resulting model has been assessed by the index of determination of the experimental and theoretical data on the linear movement speed of substrate particles on the blade of the mixer. The determination index of the experimental and theoretical data is $\eta^{2}=0.99$. The results reported here make it possible to assert the possibility of applying the proposed dependence for the theoretical modeling of the operational parameters of a drum-type reactor.

\section{References}

1. Ryabchenko, O., Golub, G., Turčeková, N., Adamičková, I., Zapototskyi, S. (2017). Sustainable business modeling of circular agriculture production: case study of circular bioeconomy. Journal of Security and Sustainability Issues, 7 (2), 301-309. doi: https://doi.org/ 10.9770/jssi.2017.7.2(10)

2. Chia, W. Y., Chew, K. W., Le, C. F., Lam, S. S., Chee, C. S. C., Ooi, M. S. L., Show, P. L. (2020). Sustainable utilization of biowaste compost for renewable energy and soil amendments. Environmental Pollution, 267, 115662. doi: https://doi.org/10.1016/j.envpol.2020.115662

3. Golub, G., Pavlenko, S., Kukharets, S. (2017). Analytical research into the motion of organic mixture components during formation of compost clamps. Eastern-European Journal of Enterprise Technologies, 3 (1 (87)), 30-35. doi: https://doi.org/10.15587/ 1729-4061.2017.101097

4. Geethamani, R., Soundara, B., Kanmani, S., Jayanthi, V., Subaharini, T. R., Sowbiyalakshmi, V., Sowmini, C. (2020). Production of cost affordable organic manure using institutional waste by rapid composting method. Materials Today: Proceedings. doi: https:// doi.org/10.1016/j.matpr.2020.02.803

5. Kalamdhad, A. S., Pasha, M., Kazmi, A. A. (2008). Stability evaluation of compost by respiration techniques in a rotary drum composter. Resources, Conservation and Recycling, 52 (5), 829-834. doi: https://doi.org/10.1016/j.resconrec.2007.12.003

6. Liu, Z., Wang, X., Wang, F., Bai, Z., Chadwick, D., Misselbrook, T., Ma, L. (2020). The progress of composting technologies from static heap to intelligent reactor: Benefits and limitations. Journal of Cleaner Production, 270, 122328. doi: https://doi.org/10.1016/ j.jclepro.2020.122328 
7. Arora, S., Rani, R., Ghosh, S. (2018). Bioreactors in solid state fermentation technology: Design, applications and engineering aspects. Journal of Biotechnology, 269, 16-34. doi: https://doi.org/10.1016/j.jbiotec.2018.01.010

8. Vechera, O., Tereshchuk, M., Chuba, V., Tsyvenkova, N. (2020). Investigation of aerobic solid fraction fermentation process parameters for organic material. 19th International Scientific Conference Engineering for Rural Development Proceedings, 1450-1455. doi: https://doi.org/10.22616/erdev.2020.19.tf363

9. Zhi-Qiang, X., Guo-Xing, W., Zhao-Chen, H., Lei, Y., Ya-Mei, G., Yan-Jie, W. et. al. (2017). Effect of Aeration Rates on the Composting Process and Loss of Nitrogen during Composting. Applied Environmental Biotechnology, 2 (1), 1. doi: https://doi.org/ 10.26789/aeb.2015.01.003

10. Kauser, H., Pal, S., Haq, I., Khwairakpam, M. (2020). Evaluation of rotary drum composting for the management of invasive weed Mikania micrantha Kunth and its toxicity assessment. Bioresource Technology, 313, 123678. doi: https://doi.org/10.1016/ j.biortech.2020.123678

11. Alkoaik, F., Abdel-Ghany, A., Rashwan, M., Fulleros, R., Ibrahim, M. (2018). Energy Analysis of a Rotary Drum Bioreactor for Composting Tomato Plant Residues. Energies, 11 (2), 449. doi: https://doi.org/10.3390/en11020449

12. Golub, G., Myhailovych, Y., Achkevych, O., Chuba, V. (2019). Optimization of angular velocity of drum mixers. Eastern-European Journal of Enterprise Technologies, 3 (7 (99)), 64-72. doi: https://doi.org/10.15587/1729-4061.2019.166944

13. Varma, V. S., Das, S., Sastri, C. V., Kalamdhad, A. S. (2017). Microbial degradation of lignocellulosic fractions during drum composting of mixed organic waste. Sustainable Environment Research, 27 (6), 265-272. doi: https://doi.org/10.1016/j.serj.2017.05.004

14. Jain, M. S., Kalamdhad, A. S. (2019). Drum composting of nitrogen-rich Hydrilla Verticillata with carbon-rich agents: Effects on composting physics and kinetics. Journal of Environmental Management, 231, 770-779. doi: https://doi.org/10.1016/j.jenvman.2018.10.111

15. Discrete numerical model for granular assemblies (1979). International Journal of Rock Mechanics and Mining Sciences \& Geomechanics Abstracts, 16 (4), 77. doi: https://doi.org/10.1016/0148-9062(79)91211-7

16. Rong, W., Li, B., Feng, Y., Schwarz, P., Witt, P., Qi, F. (2020). Numerical analysis of size-induced particle segregation in rotating drums based on Eulerian continuum approach. Powder Technology, 376, 80-92. doi: https://doi.org/10.1016/j.powtec.2020.07.101

17. Zhang, Z., Gui, N., Ge, L., Li, Z. (2017). Numerical study of mixing of binary-sized particles in rotating tumblers on the effects of end-walls and size ratios. Powder Technology, 314, 164-174. doi: https://doi.org/10.1016/j.powtec.2016.09.072

18. Ma, H., Zhao, Y. (2018). Investigating the flow of rod-like particles in a horizontal rotating drum using DEM simulation. Granular Matter, 20 (3). doi: https://doi.org/10.1007/s10035-018-0823-0

19. Verigin, Yu. A. (1989). Termodinamicheskiy analiz protsessa smeseobrazovaniya betonov i drugih dispersnyh sistem. Tez. dokl. Vsesoyuzn. konf. «Fundamental'nye issledovaniya i novye tehnologii v stroitel'nom materialovedenii». Ch. 6. Belgorod: BTISM, 72-73.

20. Hou, Z., Zhao, Y. (2020). Numerical and experimental study of radial segregation of bi-disperse particles in a quasi-two-dimensional horizontal rotating drum. Particuology, 51, 109-119. doi: https://doi.org/10.1016/j.partic.2019.09.006

21. Brandao, R. J., Lima, R. M., Santos, R. L., Duarte, C. R., Barrozo, M. A. S. (2020). Experimental study and DEM analysis of granular segregation in a rotating drum. Powder Technology, 364, 1-12. doi: https://doi.org/10.1016/j.powtec.2020.01.036

22. Li, S., Yao, Q., Chen, B., Zhang, X., Ding, Y. L. (2007). Molecular dynamics simulation and continuum modelling of granular surface flow in rotating drums. Chinese Science Bulletin, 52 (5), 692-700. doi: https://doi.org/10.1007/s11434-007-0069-4

23. Santos, D. A., Dadalto, F. O., Scatena, R., Duarte, C. R., Barrozo, M. A. S. (2015). A hydrodynamic analysis of a rotating drum operating in the rolling regime. Chemical Engineering Research and Design, 94, 204-212. doi: https://doi.org/10.1016/j.cherd.2014.07.028

24. Yari, B., Beaulieu, C., Sauriol, P., Bertrand, F., Chaouki, J. (2020). Size segregation of bidisperse granular mixtures in rotating drum. Powder Technology, 374, 172-184. doi: https://doi.org/10.1016/j.powtec.2020.07.030

25. Liu, Y., Gonzalez, M., Wassgren, C. (2019). Modeling granular material segregation using a combined finite element method and advection-diffusion-segregation equation model. Powder Technology, 346, 38-48. doi: https://doi.org/10.1016/j.powtec.2019.01.086

26. Chou, S. H., Yang, F. C., Hsiau, S. S. (2019). Influence of interstitial fluid viscosity and particle size on creeping granular flow in a rotating drum. International Journal of Multiphase Flow, 113, 179-190. doi: https://doi.org/10.1016/j.ijmultiphaseflow.2019.01.012

27. Zhang, L., Jiang, Z., Weigler, F., Herz, F., Mellmann, J., Tsotsas, E. (2020). PTV measurement and DEM simulation of the particle motion in a flighted rotating drum. Powder Technology, 363, 23-37. doi: https://doi.org/10.1016/j.powtec.2019.12.035

28. GOST 27640-88. Engineering materials and lubricants. Methods of experimental evaluation of friction coefficient. Moscow: Izdatel'stvo standartov na NPU, 22.

29. Hrabar, I. H., Hrabar, O. I., Hutnichenko, O. A., Kubrak, Yu. O. (2007). Perkoliatsiyno-fraktalni materialy: vlastyvosti, tekhnolohiyi, zastosuvannia. Zhytomyr: ZhDTU, 354.

30. Popov, V. L. (2013). Mehanika kontaktnogo vzaimodeystviya i fizika treniya. Ot nanotribologii do dinamiki zemletryaseniy. Moscow: Fizmalit, 352.

31. Vasylkovskyi, O., Leshchenko, S., Vasylkovska, K., Petrenko, D. (2016). Pidruchnyk doslidnyka. Kirovohrad, 204. 